\title{
REPENSAR OS ESTUDOS AFRICANOS Descolonizar o pensamento, questionar as práticas, reconfigurar as agendas*
}

\author{
Eduardo Costa Dias \\ ISCTE-Instituto Universitário de Lisboa, Portugal
}

\begin{abstract}
Resumo: Neste artigo, que se integra, globalmente, na crítica dos apriorismos construídos sobre natureza das realidades sociais, culturais e políticas africanas, centro-me, em particular sobre duas questões complementares mas precisas: a questão da singularidade e da "unicidade" dos africanos e de África e a da des-historização (e descontextualização) das continuidades e descontinuidades africanas. Duas questões que, cada uma à sua maneira, contribuem para aclarar as lógicas subjacentes aos quadros ideológicos e aos modi operandi em que se desenrola na actualidade a investigação, nas ciências sociais e humanas, sobre as realidades africanas.
\end{abstract}

Palavras-chave: Estudos Africanos; Agendas científicas; Lugares de enunciação; “Outras literaturas”.

Este texto parte da ideia de que, apesar dos avanços significativos empreendidos nas últimas décadas, nomeadamente pelos Estudos Africanos, a "pensabilidade" do(s) "outro(s) africano (s) negro(s)s/subsaariano(s)" e das estruturas onde ele(s) se inserem, continuam, em larga medida, devedoras de apriorismos construídos pelo "Africanismo" e por outras “ciências coloniais”. Entre outros aspectos, como veremos, nos planos da problematização e da objectivação da realidade e nos das práticas e das agendas.

Neste texto detenho-me, em particular, sobre a questão da singularidade e da "unicidade" (patentes!) dos africanos e de África e sobre a da des-historização (e descontextualização) das continuidades e descontinuidades africanas.

Duas questões precisas que se dão a ver em especial quando a reflexão incide no "como estudar as realidades africanas combatendo o etnocentrismo e o seu 'irmão gémeo', o 'particularismo africano' - essa "coisa" que durante muitos anos foi apresentada como a mais acabada das verdades, que têm marcado indelevelmente a análise das sociedades africanas e que, muito embora façam parte de um conjunto mais amplo de questões

\footnotetext{
* Este texto mantém, no essencial, o registo discursivo e a organização da comunicação apresentada no IV Congresso Internacional em Estudos Culturais - Colonialismos, Pós-Colonialismos e Lusofonias (Museu de Aveiro (Santa Joana) - Aveiro, 28, 29 e 30 de Abril de 2014).
} 
complementares entre si, têm, neste texto, por comodidade heurística, cada uma, "vida própria”.

Duas questões que, cada uma à sua maneira, contribuem para problematizar os quadros ideológicos e os modi operandi em que se desenrolam a investigações, na actualidade e nas ciências sociais, sobre as realidades africanas.

\section{1. África Negra/ África Subsaariana, expressões sem nenhum valor conceptual}

As vulgarmente ditas sociedades africanas subsaarianas, apesar da mundialização e da sua inserção plena no mundo global, vivem ainda hoje em espaços e em tempos muito contraditórias entre si, e, sobretudo, muito diferentes e variados, de tal forma que, as análises correntes, não só com muita dificuldades conseguem dar conta dos aspectos verdadeiramente singulares e separa-los dos efectivamente comuns, como suportam ainda hoje em dia a continuação da ideia de [relativo] "atraso civilizacional" dos povos africanos e a da existência de "uma-cultura-e-de-uma-mentalidade-africana-igual-portoda-a-África”.

De facto, ainda na actualidade, não só, como no Africanismo colonial, a concepção linear e evolucionista da história sobrevoa muitas análises sobre as sociedades africanas, como ainda, involuntariamente a própria expressão e, explicitamente, alguns modi operandi científicos correntemente associados ao Estudos Africanos não deixam de fomentar a ideia da existência de uma entidade africana global e, a vários títulos, "única".

Tratam-se de velhas pechas vindas de um passado longínquo e que têm marcado indelevelmente as investigações científicas sobre sociedades africanas e ainda hoje, como é facilmente constatável, longe de terem sido ultrapassadas, inclusive nos meios académicos.

De facto, como frisa Jean Copans (2010: 6-7), para muitos analistas as práticas dos povos africanos, porque relevando de uma "cultura e de uma mentalidade africana ‘típica”, são ainda hoje tomadas como práticas expeditamente extrapoláveis a "todos os africanos” e a “toda a África”, a toda a África dita África Subsaariana ou África Negra.

Uma ideia é certo, em simultâneo, hipotética e imaginada mas, no plano das práticas científicas, não menos etnocêntrica do que as do tempo da agenda colonial. Nem mais, nem menos, etnocêntrica quanto baste! 
De facto, as expressões África Negra e África Subsaariana, como aliás a de África Branca $^{1}$, não têm nenhum valor conceptual em si, não existem tanto no plano social e cultual como no plano político e económico e reenviam-nos para conjunturas políticas e científicas específicas do passado; a primeira é um “mito” geográfico de origem colonial revivificado, por razões diferentes, nos anos 1950 pelo Pan-africanismo ${ }^{2}$ e pela criação da área cultural-geográfica-científica "Estudos Africanos", a segunda, só pretensamente rompe com a tónica colonial do termo África Negra.

\section{Da persistência da "Biblioteca colonial"}

Naturalmente que a ideia e a imagem da existência de "uma entidade [continental] africana subsaariana" mais ou menos homogénea e única, não anda, como não andava a de África Negra, sozinha no mundo ou existe simplesmente porque é uma alternativa considerada politicamente correcta à expressão África Negra!

Em última análise, a persistência destas análises reenvia-nos para um facto maior e indesmentível que acompanha os países africanos deste o alvor das primeiras independências nos anos 1950, o da continuação da dependência científica, em varias situações mesmo funcional, em relação às ex-metrópoles e a consequente lenta e ainda muito inacabada ruptura com os pressupostos, os protocolos e os cânones impostos e durante muito tempo acriticamente aceites.

A "Biblioteca Colonial”, cujas raízes remontam à formação da modernidade e da identidade "ocidental" e cujo núcleo inicial foi constituído pelas descrições simplistas e racistas dos povos africanos feitas pelos missionários e viajantes e posteriormente aumentada pelos (sem conta) estudos feitos durante o período colonial, mais do que não seja porque os investigadores africanos e não africanos continuam utilizando categorias e sistemas conceptuais construídos no quadro da ordem epistemológica ocidental, permanece viva nos nossos dias (Mudimbe, 1988, 1994).

Trata-se, para além da constatação de uma situação de natureza científica, de um problema que se reenvia de per si para os problemas políticos gerais que advêm da continuada, ainda que por vias formalmente diferentes do tempo colonial, subordinação dos países africanos em relação às ex-metrópoles e mesmo, em certas

\footnotetext{
${ }^{1}$ Como as expressões África Negra e África Subsaariana, a de África Branca não tem qualquer valor conceptual e, como as duas primeiras, reenvia-nos para "adaptações de vocabulário" a conjunturas políticas, modas e outros expedientes. É, e o termo é fraco para qualificar o dislate!, uma autêntica barbaridade chamar "Arabismo" a estudos sobre a África do Norte ou, englobar, o Norte de África, para efeitos de análise, numa região, construída essencialmente, por razões militares, económicas e políticas ocidentais, chamada [Região] MONA - Médio Oriente e Norte de África.

${ }^{2}$ Ver um crítica ao papel do Pan-africanismo, nesta dimensão, por exemplo, em Appiah( 1992).
} 
dimensões, reforçada pelas novas formas de dominação impostas pela globalização e, no campo especifico da ciência, pelo mainstream ideológico e de modi operandi científicos que delas decorrem³.

De facto, as independências políticas só muito lentamente ao longo destes últimos 50/60 anos têm tido consequências no plano das alternativas académicas e científicas aos saberes dominantes. Sejam alternativas no plano das propostas analíticas, sejam, inclusive, no organizacional.

$\mathrm{Na}$ realidade, muito embora tivessem existido sempre cientistas sociais africanos de grande gabarito ombreando com os colegas do dito mundo ocidental, até há bem pouco tempo, pelas razões aduzidas em parágrafos anteriores, não se descortinavam a partir de África, nas ciências sociais e humanas, escolas de pensamento e tradições analíticas deduzidas a partir dos contextos científicos africanos, nem a larga maioria dos países africanos tinha estruturas científicas capazes de contraporem com eficácia às instituições do "Norte" as sua próprias agendas científicas.

De facto, só desde há bem pouco tempo as agendas científicas em África, se têm, no melhor sentido do termo, africanizado. Só nas últimas décadas, e apesar da persistente grave situação financeira das universidades e instituições de investigação em inúmeros países africanos, começaram a aparecer verdadeiramente investigadores e instituições nacionais, regionais e continentais capazes de contraporem, no sentido pleno do termo, com eficácia, quadros teóricos e modi operandi de sede africana aos importados e, durante décadas, geralmente acriticamente transpostos para o estudo das realidades africanas.

Nesta dimensão, a par do aumento generalizado do número e nível de formação dos cientistas sociais africanos, do crescimento acelerado do número de investigações sobre as realidades dos diferentes países africanos conduzidas por nacionais e do incremento do número e qualidade das estruturas universitária e de investigação um pouco por todo o continente, registe-se por um lado a eficaz utilização das TIC como meio de promoção e melhoria da qualidade da investigação sobre as realidades dos diferentes países africanos (ensino, publicação, internacionalização da investigação) e, por outro, o aparecimento de fóruns de discussão científica e agências de financiamento de cariz nacional, regional e continental.

\footnotetext{
${ }^{3}$ Sobre esta matéria ver, por exemplo, Abrahamsen (2003), Bertrand (2006), Estoile (2008), Gondola (2007), Mafeje (2001), Mkandawire (1995) e Pirou e Sibeaud (1997).
} 
Destas últimas registe-se, pela abrangência, objectivos e resultados, o CODESRIA Conselho para o Desenvolvimento da Pesquisa em Ciências Sociais em África.

Fundado em 1974, sediado em Dakar, inclusivo no que toca a representações nacionais e tradições científicas africanas e não africanas e progressivamente dotado dos necessários instrumentos garantes da qualidade da investigação e da equidade na alocação de financiamentos à investigação, o CODESRIA tem nas duas ultimas décadas desempenhado, entre outros, um papel incontornável na promoção a uma "escala superior" de investigações sobre realidades africanas e da edição de papers, revistas e livros de autores africanos e servido de palco a confrontos entre tradições científicas diferentes. Ao CODESRIA se deve, por exemplo, a divulgação em primeira mão, fora dos in circles, da "outra literatura científica", quer da produzida pelos, a certo momento, conhecidos como "novos intelectuais africanos", quer da produzida por intelectuais devedores de outras tradições. Os primeiros devedores em parte e os segundos na [quase] totalidade de tradições intelectuais não eurófonas4.

\section{Outros produtores, outras literaturas, contributos dos Estudos Africanos}

A familiarização crescente dos investigadores de todo o mundo com esta, tanto ao nível dos temas como dos quadros de referência, em boa parte "outra literatura científica" é, no que toca as ciências sociais e humanas, um facto maior da ultima década: inverteu a tendência diria à falta de melhor de dependência neo-colonial em termos de quadros teóricos e de modi operandi e, não menos importante, desmitificou a dita neutralidade dos agentes e dos lugares de enunciação5.

Da existência de uma outra literatura científica, de um literatura científica construída a partir de pressupostos pelo menos em parte diferentes, toda gente tem saído ganhadora, incluindo e de que maneira, os Estudos Africanos.

De facto, muito embora os Estudos Africanos se tenham destacado já desde os anos 1960 pela positiva, no que toca à luta contra o "ocidentecentrismo científico", o esforço feito nas duas últimas décadas não teria sido possível sem os contributos muito significativos vindos dos lugares africanos de enunciação.

\footnotetext{
4 Sobre a questão dos intelectuais não eurofónos em África e dos seus saberes, nomeadamente dos de tradição arabo-islâmica, ver Kane (2012) ; sobre a questão mais global das contribuições africanas para os Estudos Africanos ver, por exemplo, Hountondji (2008), Mudimbe (1988, 1994) e Melber (2009).

${ }^{5}$ Sobre este assunto, ainda que não incidindo em particular nos problemas da Historia de África, ver Bernault (2001).
} 
Na realidade, muito embora a expressão Estudos Africanos possa dar a ideia de uma visão de África como uma entidade global africana, desde há muito que estas questões têm sido debatidas e o "ocidentecentrismo" primeiro denunciado e depois, sobretudo nas duas últimas décadas, tenha começado ainda que lentamente a recuar.

Não sendo nem sinónimo de Africanismo, nem expeditamente o seu sucessor, os Estudos Africanos posicionam-se, na minha opinião, por três boas razões, no primeiro pelotão, na área das ciências sociais e humanas, da análise das sociedades africanas: interdisciplinaridade como projecto de análise antigo, testado e rodado enorme acervo de investigações e, de não somenos importância, crescente peso, nas construções teóricas e analíticas, de contribuições enunciadas a partir dos lugares africanos.

Independentemente do valor intrínseco de cada análise particular e do maior ou menor acervo de reflexões sobre as matérias, os Estudos Africanos - uma área de estudos desde há muito estruturada na sua praxis pela procura de interdisciplinaridade - são globalmente, na actualidade, em termos de produção conceptual e "maneiras de fazer", uma das tradições académicas melhores apetrechadas para estudar as realidades dos vários países africanos.

E isto não porque as realidades africanas só possam ser estudadas pelos Estudos Africanos ou porque os Estudos Africanos, em termos relativos ou absolutos, estudem melhor esta ou aquela realidade africana do que, por exemplo, na sua fileira qualquer disciplina científica isolada.

De facto, por um lado, não só todas as disciplinas e todas as combinações de disciplinas podem e devem estudar não importa qual realidade, como ainda não há nenhuma disciplina especializada numa realidade particular; por outro, e não menos importante, o que distingue as disciplinas entre si não são as eventuais diferenças de objectos reais de estudo mas sim a perspectiva a partir da qual elas os estudam.

Deste último ponto de vista, a, como atrás referi, tradição antiga, testada e rodada de interdisciplinaridade dos Estudos Africanos é uma indiscutível vantagem: consegue juntar elementos de várias disciplinas sem “matar” nenhuma disciplina.

De facto, a utilização de quadro analíticos construídos partir da interacção entre certos elementos pertencentes em maior ou menor grau a disciplinas diferentes e tendo em vista, numa situação precisa ou num lugar preciso, responder à complexidade do objecto e tudo isto sem que sem que ninguém seja obrigado a deixar de ser o que é (antropólogo, sociólogo, politólogo, economista....). 
A importância da interdisciplinaridade e a relevância que ela tem para o estudo das realidades africanas advém pois, em parte não negligenciável, de dois factos aparentemente paradoxais: transformações recíprocas entre elementos de várias disciplinas e proeminência das disciplinas.

Nesta última dimensão, dito de outra forma, mesmo nas situações mais performantes de interdisciplinaridade, as disciplinas não se esbatem, não se escondem atrás de um qualquer biombo. Os “aparatos” disciplinares não só comandam a investigação, como ainda, decorrentemente, fazem distinguir, nas areas studies em geral e na dos Estudos Africanos em particular, uns estudos dos outros.

O que a interdisciplinaridade faz, como muito bem frisa Jacques Hamel (1997:168), por via do "tráfico" de elementos entre certas disciplinas, é transformar parcialmente os modos de ver e fazer de cada uma das disciplinas. Diga-se aliás e en passant que, na actualidade, boa parte da renovação dos quadros conceptuais das disciplinas advém dos "contactos" entre disciplinas nas situações de interdisciplinaridade.

Os Estudos Africanos são não só uma área interdisciplinar como ainda tiram dessa interdisciplinaridade, sem deixar que as disciplinas fiquem para segundo plano, enormes vantagens no plano heurístico; entre outras, no plano da metodologia de análise, no da compreensão do objecto em estudo e da objectivação da realidade e no da problematização.

\section{Estudos Africanos, debates e controvérsias}

Naturalmente que nem tudo na actualidade é, como o não foi no passado, consensual no interior dos Estudos Africanos. Três grandes controvérsias, a par de outras tantas, marcaram até hoje os Estudos.

A primeira tem a ver com o próprio entendimento do que é uma área de estudos, a segunda sobre o lugar que nos Estudos Africanos ocupa a disciplina "desenvolvimento", a terceira, neste texto autonomamente tratada, a conflitualidade entre agendas nos Estudos Africanos

Não são divergências novas, embora uma, a das agendas, seja bem mais antiga do que as outras ou, dizendo talvez melhor, tenha merecido atenção mais cedo do que as outras.

Abordar a primeira controvérsia é entrar no âmago dos entendimentos e no âmbito das relações entre disciplinas e, de certa maneira, por arrastamento no sentido primeiro da 
segunda, o da velha questão da "poluição" dos Estudos Africanos pelo "desenvolvimento".

Abordar a terceira é viajar no tempo e "narrar" a história dos Estudos Africanos, isto é, em simultâneo à descrição dos seus objectivos, narrar a forma e as razões porque os Estudos Africanos, nascidos nos EUA no pós II $^{\mathrm{a}}$ Guerra Mundial, se foram institucionalizado, enquanto área de conhecimento, primeiro nos EUA, mais tarde nos países com tradições no Africanismo (as ex-potências coloniais) e mais tarde um pouco por todo o lado.

Esta controvérsia remete-nos de forma explícita para a história dos encontros e desencontros e dos conflitos e compaginações de agendas, de programas e de protagonistas.

\subsection{Os Estudos Africanos não são uma área transdisciplinar, logo não pré-configuram nenhuma disciplina}

Nos Estudos Africanos o grande confronto durante muito tempo foi entre aquelas que achavam que os modi operandi destes configuravam uma aérea de estudos interdisciplinar (area studies) e aqueles achavam que, em conjunto, o modus operandi "específico" produzido, o capital em termos de saber acumulado, o capital simbólico adquirido pelos seus scholars e as redes de instituições de grupos de investigadores entretanto criadas sobretudo na Europa e na América do Norte configurava uma situação de transdisciplinaridade e, pelo menos no médio prazo, uma disciplina científica singular e com "dignidade" igual a todas as outras chamada "Estudos Africanos"

Este debate arrastou-se durante muito tempo e também durante muito tempo os defensores da transdisciplinaridade, ainda que por vias diferentes, aproximaram-se neste plano do Africanismo e das suas intenções, diria à falta de melhor termo, monopolistas no que toca, num caso os “africanos" e, no outro, um continente, África.

De facto, tal como o Africanismo moldado aos interesses coloniais que pretendia constituir-se em disciplina, nem mais, especialmente vocacionada para estudar os "africanos" (e mesmo, nas suas declinações mais "nacional-coloniais", os "seus" africanos) $)^{6}$, "estes" Estudos Africanos pretendiam ser uma disciplina científica que estuda "África". Se no plano da escolha dos objectos reais o Africanismo e este entendimento de Estudos Africanos se separam, no plano da objectivação da realidade não deixam de partir, em gradações diferentes, de pressupostos análogos. Entre eles, o

\footnotetext{
${ }^{6}$ Ver um bom ponto de situação sobre "ciências coloniais” em Petijean (1996) ou em Mills (2002).
} 
do pressuposto da existência de "uma cultura e de uma mentalidade africana" transversal a “toda” a África, a toda a África dita África subsaariana ou África Negra

O debate sobre a natureza dos Estudos Africanos ficou quase fechado na década de 1990. O livro África and the Disciples, editado em 1993 por Robert Bates, Valentin Mudimbe e Jean O’Bar, marca simbolicamente o voltar de página deste debate nos Estudos Africano; um debate hoje quase só presente no sótão da história dos Estudos Africanos $^{7}$

\subsection{Combater a asfixia dos Estudos Africanos pelo aparato analítico "desenvolvimentista"}

Bem mais duradoura tem sido a controvérsia diria, há falta de melhor termo para definir a situação, sobre o lugar que nos Estudos Africanos ocupa a disciplina “desenvolvimento", ela sim, para um numero considerável de autores, um produto da transdisciplinaridade, um produto já no tempo do pós transdisciplinaridade.

Esta, sim, é, ao contrário da sobre a natureza dos Estudos Africanos que lentamente se foi extinguindo, uma controvérsia sem tréguas e ainda sem fim à vista!

De facto, a partir dos anos 1960 e durante muito tempo o paradigma dominante nos Estudos Africanos foi o chamado paradigma do desenvolvimento ou desenvolvimentista, um paradigma que, grosso modo, valorizando sobre tudo o resto a modernização das sociedades estimulada pelo "progresso", fazia e faz depender todas as análises dos aparatos teóricos "multiusos" induzidos a partir do "conglomerado" de teorias do desenvolvimento criadas no ocidente e exportadas.

O paradigma desenvolvimentista não só ideologicamente valoriza acriticamente o entendimento de progresso tomado no sentido que ele adquiriu a partir das teorias inicialmente esboçadas pelos filósofos das luzes, como também faz da louvação do que foi feito algures a bandeira por excelência da argumentação justificativa da bondade teórica e metodológica das suas perspectivas analíticas e, nos planos do desenho e da implementação de políticas, perfilha-se pela adaptação mais ou menos expedita de políticas experimentadas em outros quadrantes geográficos. Para quê gastar tempo a inventar de novo a roda se ela já foi inventada há muito tempo!

Das "Quintas modelo" tão em voga entre as duas Grandes Guerras às fábricas "chave na mão" dos anos imediatamente pós-independência e às teorias do desenvolvimento, primeiro, "sustentado" e, agora, "sustentável” muito em voga nestas duas últimas

\footnotetext{
${ }^{7}$ Sobre este assunto ver, para alem das referidas no livro editado por Bates, Mudimbe e O’Bar, formulações em, por exemplo, Bates (1997), Heimer (2002), Ukaegbu (1998) e Zeleza (2006).
} 
décadas e não esquecendo, nos anos 1950 e 1960, a "moda" da "extensão rural" que visava tornar cada africano, imagine-se, num camponês à europeia! ${ }^{8}$

Entre outros, três traços estão indelevelmente inscritos em todas as situações. O da praxis da imitação, o da acrítica "enfatuação sublimar" da ideologia do progressismo evolucionista e... o da recusa em tomar como igualmente boas as leituras que os outros fazem de si mesmos e das suas coisas!

Num outro plano, importa ainda referir que a ideia de desenvolvimento entendido como externamente induzido foi elaborado e implementado pela primeira nos anos 1930 nalgumas cidades inglesas e tinha em vista combater a situação de depressão económica e social em que se encontravam devido à crise económica mundial de 1929. Mais tarde, nos anos 1950, depois da constatação do fracasso da independência da Índia, foi implementado pelo poder colonial britânico no Tanganica para, nas palavras da época, "facilitar a independência" e aquando da independência, como o atesta o The Tanganyika Development Corporation Act (1962), tomado como desígnio estratégico nacional.

Assumido como "projecto estratégico" pelas burocracias estatais africanas do pósindependência e sempre financiado pelo exterior e entendido como a maior componente da modernização, no fundo entendido como instrumento de expansão geográfica das sociedades industrializadas, o paradigma desenvolvimentista teve um impacto forte nos Estudos Africanos e condiciona ainda hoje, por vezes de forma asfixiante, muitas das suas agendas de investigação ${ }^{9}$.

Na realidade, não só o paradigma de desenvolvimento foi imposto correntemente como o "chapéu teórico" das mais variadas intervenções, como ainda, por intermédio das "relações de força" geradas pela centralidade adquirida na análise das situações africanas, fez com que os Estudos Africanos rapidamente fossem "eclipsados" pelos seus interesses práticos e heurísticos, de tal forma que hoje em dia os Estudos Africanos são ainda percepcionados por muitos como “estudos de desenvolvimento".

Isto é, o paradigma do desenvolvimento fez subordinar "todas" as análises a quadros conceptuais e metodológicos aferidos pelo mainstream desenvolvimentista e, por arrastamento, fez depender a avaliação social e politica dessas análises do "grau" do seu

\footnotetext{
${ }^{8}$ Sobre este assunto "revisitar" o debate dos anos 1970-1980 sobre se "há [houve alguma vez] camponeses em África"; ver, para além do trabalho precursor de Fallers (1961), Mafeje (1985, 1992) ou Meillassoux (1975)

9 Em meados dos anos 1960 foi substituído, como desígnio nacional, pelo programa Ujaama. Hyden nos seus trabalhos sobre a Ujaama do Tanganica (1980, 1983) desmonta cirurgicamente a falácia do desenvolvimento induzido.
} 
contributo para o "desenvolvimento" da África em geral e de cada país e sociedade em particular.

Naturalmente, deixando de lado "tudo o resto" ou "simplesmente", para colocar os procedimentos analíticos no "registo" das necessidades do mainstream desenvolvimentista, deturpando quer o sentido objectivo, quer o subjectivo, das práticas culturais, sociais, políticas e económicas "correntes" e "extraordinárias" nas sociedades africanas.

O paradigma "desenvolvimentista" - versão (quase) siamesa ou, talvez melhor, versão adaptada ao novo quadro político internacional criado com as independências do paradigma "obrigação de civilizar" corrente no Africanismo colonial e cuja matriz fundadora, nos quadros mais "abertos" era, como o "progresso" e a concepção linear da história, tutelada pelo(s) evolucionismo(s).

Por exemplo, o paradigma "desenvolvimentista" ao não "sentir" necessidade de criticar os pressupostos de categorização de territórios e de povos herdados do Africanismo, não consegue avaliar e consequentemente tirar as devidas ilações das incontáveis especificidades de práticas sociais, políticas, económicas e culturais nas sociedades africanas.

"Ideologicamente", como o Africanismo do tempo colonial, a-histórico, o paradigma desenvolvimentista mete o cronómetro do tempo das sociedades africanas nos zeros: antes de nós, $\underline{o}$ tempo “inexistente”, connosco, um tempo começado do zero.

Como o Africanismo, o paradigma desenvolvimentista é um promotor activo e intencional da des-historização (e descontextualização) das continuidades e descontinuidades africanas.

Neste sentido, os Estudos Africanos, para romperem definitivamente como novo ocidentecentrismo que se "projectou", via sobretudo a dominação do paradigma desenvolvimentista, do Africanismo para os Estudos Africanos, devem dotar-se de uma nova agenda ${ }^{10}$.

Uma agenda que, por um lado, liberte os Estudos Africanos dos quadros teóricos e metodológicos, das cangas ideológicas e das agendas do mainstream do desenvolvimento e que, por outro, privilegie, em simultâneo, a aferição das práticas pelo "tempo" das sociedades africanas, a análise das dimensões endógenas das

\footnotetext{
${ }^{10}$ Sobre a questão da nova agenda para os Estudos Africanos ver, por exemplo, Hountondji (2008), Kane (2003), Mama (2007), Melber (2009), Mudimbe (1994), Ricard (2004) e Zeleza (2007a, 2007b); ver ainda alguns textos da colectânea organizada por Mkandawire (2005)
} 
sociedades africanas e da interacção destas com os fenómenos globais e combata a persistente "insularidade" dos Estudos Africanos, paradoxalmente reforçada pelo mainstream desenvolvimentista.

$\mathrm{Na}$ actualidade, para os Estudos Africanos, muito mais importante do que um qualquer exercício de "revisitação" das diferentes escolas do desenvolvimento ou de formulação de perspectivas de análise aferidas pelas "necessidades do desenvolvimento", é, por exemplo, entre inúmeros outros excelentes exemplos, analisar as razões e as consequências, do colapso do Estado em África e da desintegração das sociedades africanas ou as formas populares de resposta à ausência de Estado

É preciso, também nos Estudos Africanos, “olhar” para “as Áfricas” de uma outra forma! É preciso compaginar as continuidades e descontinuidades africanas com, passe o envelhecimento do termo, os "processos históricos" das sociedades africanas.

É nesta dimensão que desde há alguns anos os contributos dos investigadores africanos se têm mostrado decisivos, levando mesmo alguns observadores amantes de "frases fortes" a dividirem o tempo nos Estudos Africanos em duas partes: antes e depois.

\section{Agendas, programas e protagonistas}

Independente de tudo resto e dando de barato a eventual bondade ou não da divisão desta forma do tempo nos Estudos Africanos, o papel dos investigadores africanos levanos directamente para a questão das agendas, para a dos Estudos Africanos em comparação com a do Africanismo e para a questão incontornável da natureza da sua agenda inicial e da sua evolução até as nossos dias.

Os Estudos Africanos, no jargão da classificação científica, Área de Estudos Africanos, foram "inventados" nos EUA no pós II a Guerra Mundial a par de outras Áreas de Estudos (Ásia, América Latina, Índia, Médio Oriente, "Insulíndia”, etc). No plano politico, a criação de centros de investigação e departamentos universitários configurados a partir de Áreas geográfico-culturais correspondia à necessidade de quem, em 1945, se tinha transformado no dono de meio mundo, conhecer as "suas" terras e as "terras" que disputavam com o dono do outro meio mundo.

Razão tanto mais importante dada a pequena, em tempo e em extensão, experiência dos EUA enquanto potência colonial, dito de uma forma mais precisa enquanto potência colonial "ultramarina". 
Não nos iludamos a razão primeira foi, como aliás a do Africanismo, política. A montagem científica preparada para os Estudos Africanos foi, nessa altura, em boa parte um instrumento de credibilização pela ciência dos objectos políticos.

Só a partir de finais dos anos 1950 nos Estudos Africanos, entretanto estendido a outras academias ocidentais - caso em $1^{0}$ lugar da Inglaterra, a dimensão científica começa a ganhar alforria face ao interesse politico directamente imposto.

A partir de finais da década de 1960 nos EUA, como no resto das academias, os Estudos Africanos dão-se a ver sobretudo pela sua dimensão scholar e científica.

As orientações políticas governamentais a partir da década de 1960 nos Estudos Africanos revelam-se, sobretudo, pela "expertise" pedida pelas múltiplas "agências" e pelos financiamentos selectivos à investigação.

Verdade provada para os EUA, verdade provada igualmente para os países europeus que por essa época vêm quase todas as suas colónias em África tornarem-se em países independentes.

Inicialmente orientados para a análise das dimensões políticas e afins, os Estudos Africanos acabam com o correr dos anos por "tocar" todas as disciplinas das ciências sociais, humanas e afins.

Todavia, para além de outras, com uma diferença de fundo ao Africanismo. De facto, ao contrário do Africanismo, pelo menos do Africanismo que "correu" no período áureo do colonialismo (+/-1890 - +/-1940), em que o objectivo era conhecer o "homem africano" e só por arrastamento as sociedades, nos Estudos Africanos o objectivo sempre foi desde o inicio, mesmo no tempo em que estava ainda muito "agarrado" ao interesse politico dos países do norte, conhecer as sociedades/os países africanos.

Uma diferença de tombo constatável pela simples comparação das agendas.

No Africanismo, uma agenda iniciada pelo conhecimento da língua que falam os "nossos africanos" e, num primeiro tempo, continuada, entre outras, pelo procurar conhecer as manifestações culturais, sociais e religiosas dos "nossos africanos"

Nos Estudos Africanos, uma agenda durante algum tempo quase que só centrada na análise das movimentações políticas nos diferentes futuros países africanos independente. Esta opção não é inócua por parte das então potências coloniais e, sobretudo, por parte dos Estados Unidos. 
Convém ainda referir, ainda que brevemente, quais os tipos de pessoal afecto aos trabalhos do Africanismo e aos dos Estudos Africanos.

No Africanismo, primeiro os missionários, depois os funcionários da administração colonial e os membros europeus das forças armadas e só mais tarde antropólogos, sociólogos, geógrafos e outros especialistas, na larga maioria dos países até finais dos anos 1950 formados nas escolas superiores coloniais ${ }^{11}$.

De facto, na Europa, a "matérias africanas" eram ainda no início dos anos 1960 quase exclusivamente leccionadas nas instituições vocacionadas para formação de funcionários coloniais. Nas área da ciências sociais, humanas e afins, as excepções eram poucas e quase sempre dependente do "peso" de quem leccionava as cadeiras ou o "peso" na respectiva academia da tradição da Antropologia Física.

Nos Estudos Africanos, nos Estados Unidos desde o início independentemente do facto irrecusável de polarização nas temáticas políticas, profissionais provindos das mais diferentes origens disciplinares e organizados em departamentos próprios em "faculdades normais"12.

$\mathrm{Na}$ Europa, os Estudos Africanos foram inicialmente leccionados por alguns africanistas reclassificados/recauchutados e pouco mais tarde também por uma nova geração de scholars, em vários casos vindos das lutas anticoloniais dos anos 1950princípios dos de 1960, com outros percursos escolares e pessoais.

Se a "primeira viragem" tem a ver com o ganho, por volta de finais dos anos 1960, pelos Estudos Africanos de relativa autonomia face às agendas governamentais e, sobretudo na Europa, pela "recauchutagem" de alguns antigos africanistas e pelo aparecimentos de uma nova geração de scholars, a "segunda viragem" tem tudo a ver com o início da participação plena dos scholars africanos ${ }^{13}$. Uma viragem lentamente iniciada a partir de finais dos anos 1980.

Uma participação decisiva devida, como vimos em pontos anteriores, não só ao seu papel na enunciação, mas também ao seu papel cada vez mais incontornável na definição de programas e, claro, de agendas científicas nos Estudos Africanos.

\footnotetext{
11 Ainda que centrada no caso das colónias francesas, uma boa descrição da evolução da figura de “especialista em "indígenas" em Donato (1988) e, sobretudo, em Dimier (2004), Estoile (2000, 2002) e Pereira (1998).

${ }^{12}$ Sobre este assunto, ver Ferreira (2010), Keller (1988) ou Szanton (2003)

${ }^{13}$ Fica por referir neste texto o papel dos afro-americanos e a, vários títulos dos Africana Studies, Black Studies, African-American Studies na "montagem" e estabilização dos Estudos Africanos nos Estados Unidos e dos intelectuais africanos no Africanismo e nos primeiros anos dos Estudos Africanos na Europa; de forma nenhuma e em nenhuma situação papéis desprezíveis.
} 
Confrontados com uma nova vaga de "investigadores apressados" e com termos de referência intencionalmente precisos e orientados (e por eles raramente questionados), os Estudos Africanos contam sobretudo com os scholars africanos para pela qualidade, profundidade e criatividade dos seus trabalhos lhes fazerem frente. Com os scholars africanos e com as redes africanas de investigação que eles pacientemente foram tecendo e globalizando e, não menos importantes, os estudantes que eles têm vindo a formar.

De facto, os protagonistas decisivos começam a ser, num já razoável número de casos, os que enunciam os Estudos Africanos dos lugares africanos.

Os scholars africanos não só estão invertendo a dependência neo-colonial em termos de quadros problemáticos e de modi operandi como e, não menos importante, contribuem decisivamente para desmitificar, uma das verdades acabadas trazidas por arrasto pela "Biblioteca Colonial", a da aparente neutralidade dos agentes e dos lugares de enunciação.

Um facto maior nos Estudos Africanos: o da desmitificação da aparente neutralidade dos agentes e dos lugares de enunciação do discurso científico.

\section{Referências bibliográficas}

Appiah, Kwame (1992). In My Father's House: Africa in the Philosophy of Culture, Londres, Methuen

Abrahahamsen, Rita (2003) 'African Studies and the postcolonial challenge', African Affairs, $102:$ 189-210.

Bates, Robert, Valentin Y. Mudimbe e Jean O'Barr (eds) (1993) Africa and the Disciplines - The contribuitions of Research in Africa to the Social Sciences and Humanities, Chicago, University of Chicago Press.

Bernault, Florence (2001). 'L'Afrique et la modernité des sciences sociales', Vingtième siècle. Revue d'histoire, 70 : 127-138.

Bertrand, Roman (2006). "Les sciences sociales et le « moment colonial »- De la problematique de la domination coloniale a celle de l'hegemonie imperiale", Questions de Recherche - CERI, 18

Copans, Jean (2010). Un demi-siècle d'africanisme africain, Paris, Karthala

Dimier, Véronique (2004). 'Le Comandant de Cercle - Un 'expert' en administration coloniale, un 'spécialiste' de l'indigène', Revue d'Histoire des Sciences Humaines, 10 : 39-57.

Estoile, Benoît de l' (2008). "The past as it lives now: an anthropology of colonial legacies', Social Anthropology, $3:$ 267-279. 
Estoile, Benoît de l' (2000). "Savoirs anthropologiques, administration des populations et construction de l'Etat ", Revue de Synthèse, $\mathrm{n}^{\circ}$ 3-4 : 233-263.

Estoile, Benoît de l' (2002). "Ciência do homem e 'dominação racional': saber etnológico e política indígena na África Colonial Francesa”in Benoît de l'Estoile, Federico Neiburg e Lygia Sigaud (eds), Antropologia, Impérios e Estados Nacionais, Rio de Janeiro, FAPERJ : 61-93.

Fallers, Lloyd (1961). 'Are African Cultivators to Be Called "Peasants"? 'Current Anthropology, 2 : 108-110

Ferreira, Roquinaldo (2010). “A institucionalização dos Estudos Africanos nos Estados Unidos: advento, consolidação e transformações”, Revista Brasileira de Historia, 59: 79-90

Gallo, Donato (1988) Antropologia e Colonialismo - o Saber Portugues, Lisboa, ERHeptágono

Gondola, Charles Didier (2007). Africanisme: la crise d'une illussion, Paris, Harmattan.

Hamel, Jaques (1997). Précis d'Épistémologie des Sciences Sociales, Montreal, Harmattan.

Heimer, Franz (2002). "Reflexões acerca de uma abordagem interdisciplinar das sociedades”, Cadernos de Estudos Africanos, 3: 153-159

Hountonddji, Paulin J. (2008). 'Conhecimento de África, conhecimento de Africanos: Duas perspectivas sobre os Estudos Africanos', Revista Crítica de Ciências Sociais, 80: 149-160

Hydén, Göran (1983). No Shortcuts to Progress, Los Angeles, University of California Press.

Hydén, Göran (1980). Beyond Ujamaa in Tanzânia - Underdevelopment and an Uncaptured Peasantry, Los Angeles, University of California Press.

Kane, Ousmane (2012). Non-Europhone Intellectuals, Dakar, CODESRIA.

Keller, Edmond (1988). Globalization, African Studies and the Academy, Bordeus, CEAN

Mafeje, Archie (2001). "Anthropology in Post-Independence Africa: end of an era and the problem of self-redefinition", in Archie Mafeje (ed), African Social Scientists Reflections [Part 1], Nairobi, Heinrich Boll Foundation: 28-74

Mafeje, Archie (1992). "Agregados e Perspectivas de Relançamento da Agricultura na África ao Sul do Saara", in Ciências Sociais em África - Alguns Projectos de Investigação, Dakar, CODESRIA: 233-281.

Mafeje, Archie (1985). "Africa Peasants: An Historical Anomaly?", Africa Development, 3241-257. 
Mama, Amina (2007). "Is It Ethical to Study Africa? Preliminary Thoughts on Scholarship and Freedom”, African Studies Review, Vol. 50, No. 1: 1-26

Melber, Henning (2009). "The Relevance of African Studies", Wiener Zeitschrift für kritische Afrikastudien, 9: 183-200.

Meillassoux, Claude (1975). Femmes, greniers et capitaux, Paris, Maspero.

Mills, David (2002). "British Anthropology at the End of Empire : the rise and fall of the Colonial Social Science Research Council, 1944-1962", Revue d'Histoire des Sciences Humaines, $6: 161-188$

Mkandawire, Thandika (1997). "The Social Sciences in Africa: Breaking Local Barriers and Negotiating International Presence", African Studies Review, Vol. 40, No. 2: 15-36

Mkandawire, Thandika (ed) (2005). African Intellectuals - Rethinking Politics, Language, Gender and Development, Londres, Zed Books

Mudimbe, Valentin Y. (1988). The Invention of Africa: Gnosis, Philosophy and the Order of Knowledge, Bloomington: Indiana University Press

Mundimbe, Valentin Y. (1994). The Idea of Africa, Bloomington, Indiana University Press.

Pereira, Rui (1986). "A antropologia aplicada na política colonial portuguesa do Estado Novo.” Revista Internacional de Estudos Africanos, 4/5, 191-235.

Petitjean, Patrick (ed) (1996). Les SciencesColoniales - Figures et institutions, Paris, ORSTOM.

Pirou, Anne e Emmanuelle Sibeud (eds) (1997). L'Africanisme en Questions, Paris, Centre d'Études Africaines-EHESS.

Ricard, Alain (2004). "De l'Africanisme aux Études Africaines - Textes et 'Humanités'." Afrique \& Histoire 2: 171-192.

Szanton, David (ed) (2004). The Politics of Knowledge - Area Studies and the Disciplines, Berkeley, The University Califórnia Press

Ukaegbu, Chikwendu Christian (1998). "Commentary: area studies and the disciplines." Africa Today, 45 (3-4): 323-336

Zeleza, Tiyambe. (ed) (2006). The Study of Africa. Disciplinary and Interdisciplinary Encounters (Vol I). Dakar: CODESRIA.

Zeleza, Tiyambe. (ed). (2007a). The Study of África - The Global and Transnational Engagements (Vol II). Dakar: CODESRIA.

Zeleza, Tiyambe. (2007b). African Studies from a Global Perspective, Symposium for Human Rights and Leadership in Africa at London Metropolitan University, UK on 4 October 2007. 
Eduardo Costa Dias, Doutor em Antropologia Social, professor no Departamento de Ciência Política e Políticas Públicas, investigador no Centro de Estudos Internacionais e director do Doutoramento em Estudos Africanos do ISCTE - Instituto Universitário de Lisboa. Tem desenvolvido, na vertente África, trabalhos sobre a Questão fundiária, o Estado, as Relações entre o islão e o Estado, a Transmissão de saberes nas sociedades muçulmanas africanas e, mais recentemente, sobre a Natureza das Forças Armadas e sobre a "geopolítica" dos tráficos e rebeliões na região do Saara - Sahel e do Noroeste africano.

eduardocostadias@yahoo.fr 